\title{
Analysis of Weld Joint for SS 316 Material Using Taguchi Technique
}

\author{
Ankita A. Kashid, Pallavi M. Patil, Monika R. Olekar, \\ Priydarshani V. Deshmane, Sonali S. Jadkar
}

\begin{abstract}
The S.S 316 is a chromium-nickel-molybdenum austenitic stainless steel developed to provide improved corrosion resistance to $\mathrm{S.S} 304 / 304 \mathrm{~L}$ in moderately corrosive environments. 316stainless steel is selected over other materials because of its distinct properties, cheaper cost and its availability in the market. 316stainless steel used is a boiler grade steel used in pressure vessels. Type 316 stainless steel is broadly used in application demanding corrosion resistance superior to Type 304, or good elevated temperature strength. Typical uses include exhaust manifolds, furnace parts, heat exchangers, jet engine parts,tanks, evaporators, paper and textile processing equipment.. The addition of molybdenum improves general corrosion and chloride pitting resistance. TIG welding is most popular method for welding of stainless material. SS316 is commonly used for producing milk silo in dairy industry. The objective behind this research is to optimize process parameter and to determine the influence of process parameter on the quality of weld. Welding current and Gas flow rate is process parameter selected for experimental work. In this research Taguchi method is used to optimize welding current and Gas flow rate. In this project work, X-ray radiographic test has been conducted in order to detect surface and subsurface defects of weld specimens made of SS 316 austenitic stainless steels. Effect of current, gas flow rate and metal plate thickness on quality of weld in metal inert gas arc welding of SS316 austenitic stainless steel has been studied in the present work through experimental analysis. Butt welded joints have been made by employing different levels of gas flow rate, current, and plate thickness. The quality of the weld has been assigned in terms of yield strength, ultimate tensile strength and percentage elongation of welded specimens. The observed data have been interpreted, discussed and analyzed using Taguchi methodology.
\end{abstract}

Index Terms - Weld Joint, Taguchi Technique .

\section{INTRODUCTION}

GTAW or TIG welding process is an arc welding process adopt a non consumable tungstenelectrod. For producing the weld, the are of weld is protected from atmosphere with a shielding gas generally Argon or Helium or sometimes mixture of Argon and Helium. A filler metal may also supply with material manually for proper welding. GTAW most commonly called TIG welding process was developed during

Ankita A. Kashid,Mechanical Engineering, SVERI's College of Engineering Pandharpur.

Pallavi M. Patil, Mechanical Engineering,SVERI's College of Engineering ,Pandharpur

Monika R. Olekar, Mechanical Engineering, SVERI's College of Engineering Pandharpur

Sonali S. Jadkar, Mechanical Engineering, SVERI's College of Engineering

Priydarshani V. Deshmane ,Mechanical Engineering, SVERI's College of Engineering Pandharpur the Second World War.

With the development of TIGwelding process, welding is difficult to weld materials e.g. Aluminium and Magnesium becomes possible. The use of TIG today has spread variety of metals like stainless steel, mild steel and high tensile steels, Al alloy, Titanium alloy. Like other welding system, TIG welding power sources have also improved from basic transformer types to the highly electronic controlled power sourcetoday.This type of weld also allows for intricate detailing, which is an important consideration in custom iron - especially in designs that have ornate scrolls and other design elements.Other welding techniques leave slag behind, and this has to be cleaned up and removed before the design can be completed. This method, however, generally leaves no slag behind, which means fabricator can spend more time on creating design, rather than cleaning up messy welds. Taguchi involves using orthogonal arrays to order the parameters affecting the process and the levels at which they should be varied. This allows for collection of the required data to determine the factors which are mainly affect s on the product quality with minimum amount of experimentation, thus it saving time and resources. The Taguchi method is used when there are intermediate number of variables (3 to 50), few interactions between the variables, and when only a few variables contribute remarkable. A large number of experiments were to be carried out when the number of process parameters are increase. To solve this problem, the Taguchi method is uses a special design of orthogonal arrays for studying the entire parameter space with only a minimum number of experiments. Three parameters are to be considered as controlling factors, that are welding current, gas flow rate and material thickness. Each parameter having three levels viz. low, medium and high, normally denoted by 1, 2 and 3, respectively. According to the Taguchi method, if three parameters and 3 levels for experimentation, L9orthogonal array should be employed for the experimentation. In this work L9 orthogonal array is sufficient to predict the required results. It would require total 27 experiments to enhance the parameters.

\section{A. Basic mechanism of TIG welding:}

TIG welding is arc welding process which uses a non-consumable tungsten electrode to produce the weld on the component. The weld area is protected from atmosphere by providind an inert shielding gas (helium or argon), and a filler metal is usually employed. The power is supplied from source of power (rectifier), through a welding torch and is delivered to a tungsten electrode. An electric arc is further generated between the work piece and tungsten electrode 
using a constant-current welding power supply which produces energy and conducted across the arc through a highly ionized gas and metal vapours. The electric arc can produce temperatures up to $20,000 \mathrm{oC}$ and this heat can be focused to melt and join two different parts of material. The schematic diagram of TIG welding and mechanism of TIG welding is as shown in below fig. 1

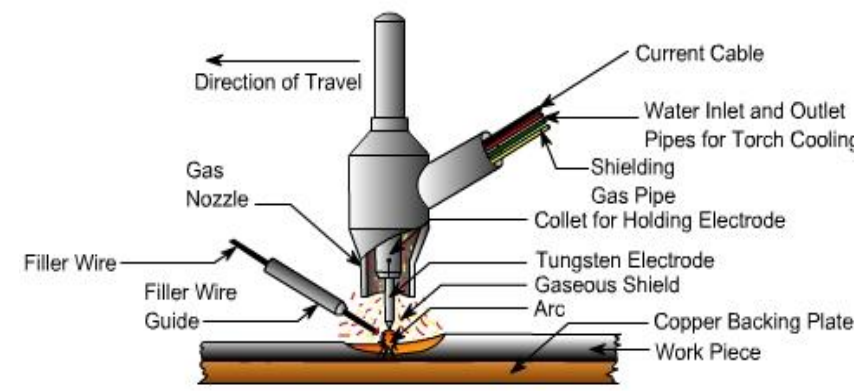

Fig 1 schematic representation of TIG welding [1].

\section{B. General Information of SS-316}

Table 1 :Technical Information of SS-316[1].

\begin{tabular}{|l|l|l|}
\hline Alloy & UNS Number & SAE Number \\
\hline 316 & S31600 & 30316 \\
\hline
\end{tabular}

Types 316 and $316 \mathrm{~L}$ are more resist to atmospheric and other mild types of corrosion as compared to the 18-8 stainless steels. Type 304 stainless steel is considered to resist the pitting and crevice corrosion in waters containing up to about $100 \mathrm{ppm}$ chlorides At temperature as high as $120^{\circ} \mathrm{F}$ $\left(49^{\circ} \mathrm{C}\right)$, Type 316 is more resistant to concentration of this acid up to the 5 percent. At temperature range under $100^{\circ} \mathrm{F}$ $\left(38^{\circ} \mathrm{C}\right)$, this type has higher resistance to higher concentrations. Where condensation of sulphur-bearing gases occurs, these alloys are much more resistant as compared to other stainless steel types. In such applications, however, the acid concentration has marked impact on the rate of attack and should be carefully examined. The molybdenum-bearing Type 316 stainless steel also provides resistance to the wide variety of other environments.

\section{Literature Review}

TIG welding is widely used for different types of metal \& alloy welding and still lot of research work is going for effective performance by TIG welding process. Kishore et al. [1]: In this paper they had done research on AISI1040 steel by using taguchi method. Research on the welding of material like steel is still difficult and ongoing.Exhaustive survey suggest that 5-7 control factors . The data in the present work is collected using ultrasound testing (UT), in which angle beam technique is used for the testing of weldments and results are quantified. Harish Kumar et al. [2]: In this paper they had done research on austenitic stainless steel. Nitrogen alloyed austenitic stainless steels are designated as $316 \mathrm{LN}$ which contain the low carbon due to which the risk of sensitization can be deminish. This paper addresses the laser welding aspects, which may be of considerable interest because it offers several advantages over other welding processes. Magudeeswaran et al.[3]: The activated TIG (ATIG) welding process primarily focuses on increasing the penetration depth and the reduction in the weld bead width has not been paid much attention. The enhance process parameters are reported as $1 \mathrm{~mm}$ electrode gap, $140 \mathrm{~A}$ current, $130 \mathrm{~mm} / \mathrm{min}$ travel speed, and $12 \mathrm{~V}$ voltage. Bharatha et al. [4]: The objective of this research is used to determine the influence of various welding parameters on the weld bead of AISI 316 welded joint. In this research work the ANOVA technique is used to identify the influence of the welding speed, current, electrode, root gap on the strength of the material. The result shows that speed is most influencing factor to have highest bend strength and current that is to be used while welding is the most influencing factor to get higher tensile strength. Buddu et al. [5]: The development of advanced fusion reactors like DEMO will have various challenges in materials and fabrication. The double walled design for vacuum vessel with thicker stainless steel material (40-60 mm) has been schemed in the advanced fusion reactors like ITER. The present paper describes characterization of welding joints of SS316L plates with higher thicknesses like $40 \mathrm{~mm}$ and $60 \mathrm{~mm}$, prepared using multi-pass Tungsten Inert Gas (TIG) welding process. The weld quality has been evaluated with non-destructive tests by $\mathrm{X}$-ray radiography and ultrasonic methods. Balaji et al. [6]: The joining of similar grades of stainless steel by TIG welding with the various parameters like current, gas flow rate, and bevel angle is reported and the SS $316 \mathrm{~L}$ is selected over the other grades due to its less carbon content.

\section{Scope}

Only one material SS-316 grade stainless steel has been considered in this project. The materials other than this or different material may be considered in future. More than one material will be consider for future work. In this experiment only weld defects and Tensile strengths are considered. In future, the other than weld defects and weld strength, other test may be considered for analysis such as bending test, microstructure test, hardness test etc. Forthis work only current, gas flow rate, thickness is considered. In future, other than current, gas flow rate, thickness, another parameter may be considered such as voltage, speed, root gap, nozzle to workpiece distance etc. In this experiment consider only 3 levels and 3 parameters i.e. L9 orthogonal array is selected for experimentation. In future more than 3 levels and 3 parameters may be considered. For more levels and parameters get high accuracy in result and get more reliable parameters for TIG welding.

\section{MATERIALS AND METHODOLOGY OF SS-316}

The Chemical Composition of SS-316 is given in below Table 2

\begin{tabular}{|c|c|c|c|c|c|c|c|c|c|c|}
\hline Alloy & $\mathrm{C}$ & $\mathrm{Mn}$ & $\mathrm{P}$ & $\mathrm{S}$ & $\mathrm{Si}$ & $\mathrm{Cr}$ & $\mathrm{Ni}$ & $\mathrm{Mo}$ & $\mathrm{Cu}$ & $\mathrm{N}$ \\
\hline 31 & .0. & 2.0 & .0 & .0. & 1. & $16.00-18.0$ & $10.00-14.0$ & $2.00-3.0$ & 0.7 & - \\
6 & $8 \%$ & $0 \%$ & $4 \%$ & $3 \%$ & $0 \%$ & $0 \%$ & $0 \%$ & $0 \%$ & $5 \%$ & \\
\hline
\end{tabular}


International Journal of New Technology and Research (IJNTR)

ISSN: 2454-4116, Volume-5, Issue-4, April 2019 Pages 30-33

\section{A. Design of Orthogonal array by using Taguchi method}

The following is the experimental procedure which is done in this project such as follows:-

1. Commercial SS-316 plate of thickness 3, 5, $8 \mathrm{~mm}$ will be selected as work piece material for the present experiment.

2. SS-316 plate will be cut with dimension of $100 \mathrm{~mm} \times 50$ $\mathrm{mm}$ with the help of band-saw and grinding done at the edge to smooth the surface to be joined. The dimensions will have taken by references of research papers.

3. After cutting material into dimensions go for Taguchi method, for this decided 3 levels i.e. low medium and high and 3 parameters i.e. welding current, gas flow rate, material thickness. These three parameters were taken as variable for present study and their three levels were chosen for which responses were measured, for which L9 orthogonal array was selected as experimental design method. These parameters with their levels were shown in table 3.

4. After that surfaces will polished with emery paper to remove any kind of external material. Before welding all sheets were cleaned chemically by acetone in order to remove any source of contaminants like rust, dust oil etc.

5. After sample preparation, SS-316 plates are fixed in the working table with flexible clamp side by side and welding done so that a butt join can be formed.

6 . Then TIG welding on plates will done by using Taguchi array design.

7. After that for Non Destructive Testing i.e. Radiography Testing.

8. After getting result of Radiography testing means for Destructive testing i.e. tensile testing.

Table 3 : Process parameters and levels

\begin{tabular}{|c|c|c|c|c|}
\hline Paramete & Unit & Level & Level & Level \\
\hline $\begin{array}{c}\text { Welding } \\
\text { current }\end{array}$ & $\mathrm{A}$ & 125 & 137 & 151 \\
\hline $\begin{array}{c}\text { Gas } \\
\text { Flow Rate }\end{array}$ & $1 / \mathrm{min}$ & 18 & 21 & 24 \\
\hline $\begin{array}{c}\text { Metal } \\
\text { Plate } \\
\text { Thickness }\end{array}$ & $\mathrm{mm}$ & 3 & 5 & 8 \\
\hline
\end{tabular}

Once the orthogonal array is selected, the experiments are carried out as per the level combinations. It is important that all experiments are to be conducted. The performance parameters (output) are noted for each experimental run for analysis.In below

Table 4 the experimental design using orthogonal array is shown:

Table 4 : Experimental design using orthogonal array

\begin{tabular}{|c|c|c|c|}
\hline \multirow{2}{*}{$\begin{array}{c}\text { Experime } \\
\text { number }\end{array}$} & \multicolumn{3}{|c|}{ Levels } \\
\cline { 2 - 4 } & $\begin{array}{c}\text { Welding } \\
\text { Current }\end{array}$ & $\begin{array}{c}\text { Gas Flow } \\
\text { Rate }\end{array}$ & Thickness \\
\hline 1 & $125 \mathrm{~A}$ & $181 / \mathrm{min}$ & $3 \mathrm{~mm}$ \\
\hline 2 & $125 \mathrm{~A}$ & $211 / \mathrm{min}$ & $5 \mathrm{~mm}$ \\
\hline 3 & $125 \mathrm{~A}$ & $241 / \mathrm{min}$ & $8 \mathrm{~mm}$ \\
\hline 4 & $137 \mathrm{~A}$ & $181 / \mathrm{min}$ & $3 \mathrm{~mm}$ \\
\hline 5 & $137 \mathrm{~A}$ & $211 / \mathrm{min}$ & $5 \mathrm{~mm}$ \\
\hline 6 & $137 \mathrm{~A}$ & $241 / \mathrm{min}$ & $8 \mathrm{~mm}$ \\
\hline 7 & $151 \mathrm{~A}$ & $181 / \mathrm{min}$ & $3 \mathrm{~mm}$ \\
\hline
\end{tabular}

\begin{tabular}{|l|l|ll|l|}
\hline 8 & $151 \mathrm{~A}$ & 21 & $1 / \mathrm{min}$ & $5 \mathrm{~mm}$ \\
\hline 9 & $151 \mathrm{~A}$ & 24 & $1 / \mathrm{min}$ & $8 \mathrm{~mm}$ \\
\hline
\end{tabular}

\section{RESULT AND DISCUSSION}

In this total 9 experiments were taken as L9 orthogonal array is selected. In this paper only 4 experiments were added as per optimized result.

\section{A. Experiment no.1}

First take Radiography test on weld coupon by using ASME SEC-V \& SEC IX. The Tensile test is conducted on the SS316 Tig weldment on a Universal Testing Machine as per ASTM A370-2017 standards to determine the ultimate tensile stress of the weldment. For first experiment following parameters are considered. Table 5 and Table 6 shows the radiography result and tensile test result respectively.

Table 5 Radiography Result of 1st test coupon.

\begin{tabular}{|l|c|c|}
\hline $\begin{array}{l}\text { Film Size } \\
\text { (in inches) }\end{array}$ & Identification No. & Observation \\
\hline $3 \times 5$ & $\begin{array}{c}\text { SVERI/TIG/TC4 } \\
\text { AB }\end{array}$ & Min PO \\
\hline
\end{tabular}

Table 6 Tensile test result of 1 st weld coupon

\begin{tabular}{|l|l|c|}
\hline Sr.No & Parameter/Description & $\begin{array}{c}\text { Actual } \\
\text { Value }\end{array}$ \\
\hline 1 & Thickness & 8.02 \\
\hline 2 & Width & 20.00 \\
\hline 3 & Area & 160.80 \\
\hline 4 & $\begin{array}{l}\text { Ultimate Tensile } \\
\text { Strength }\end{array}$ & 615.00 \\
\hline 5 & Ultimate Tensile Load & 99.00 \\
\hline 6 & Specimen Shape & FLAT \\
\hline 7 & Fracture & WELD \\
\hline
\end{tabular}

In this experiment welding current 125A, gas flow rate 24 $1 / \mathrm{min}$, thickness $3 \mathrm{~mm}$. Minimum porosity is obtained in radiography test and get tensile strength about $615 \mathrm{~N} / \mathrm{mm} 2$. Here weld joint is acceptable.

\section{B. Experiment no.2}

For second experiment following parameters are considered and The below Table 7 and Table 8 shows the tensile test result and radiography test result respectively.

Table 7 Result of Tensile test of 2nd weld coupon

\begin{tabular}{|l|l|c|}
\hline Sr.No & Parameter/Description & $\begin{array}{c}\text { Actual } \\
\text { Value }\end{array}$ \\
\hline 1 & THICKNESS & 3 \\
\hline 2 & WIDTH & 20 \\
\hline 3 & AREA & 60 \\
\hline 4 & $\begin{array}{c}\text { ULTIMATE } \\
\text { TENSILE STRENGTH }\end{array}$ & 600 \\
\hline 5 & $\begin{array}{l}\text { ULTIMATE } \\
\text { TENSILE LOAD }\end{array}$ & 36 \\
\hline 6 & SPECIMEN SHAPE & FLAT \\
\hline 7 & FRACTURE & WELD \\
\hline Table 8 Radiography result of 2 ${ }^{\text {nd }}$ weld coupon. \\
\hline Film size & Identification No. & Observation \\
\hline
\end{tabular}




\begin{tabular}{|c|l|l|}
\hline (in inches) & & \\
\hline $3 \times 5$ & $\begin{array}{c}\text { SVERI/TIG/TC4 } \\
\mathrm{AB}\end{array}$ & NSD \\
\hline
\end{tabular}

In this experiment welding current $125 \mathrm{~A}$, gas flow rate 18 $1 / \mathrm{min}$, thickness $8 \mathrm{~mm}$. No any defect is obtained in radiography test and get tensile strength about $600 \mathrm{~N} / \mathrm{mm} 2$. Here weld joint isacceptable.

\section{Experiment no.3}

For third experiment following parameters are considered.

The below Table 9 and Table 10 shows the result of tensile test and radiography test respectively

Table 9 Result of Tensile test of $3^{\text {rd }}$ weld coupon

\begin{tabular}{|l|l|l|}
\hline Sr.No & Parameter/Description & $\begin{array}{c}\text { Actual } \\
\text { Value }\end{array}$ \\
\hline 1 & THICKNESS & 3 \\
\hline 2 & WIDTH & 20 \\
\hline 3 & AREA & 60 \\
\hline 4 & $\begin{array}{l}\text { ULTIMATE } \\
\text { TENSILE STRENGTH }\end{array}$ & 583.00 \\
\hline 5 & $\begin{array}{l}\text { ULTIMATE } \\
\text { TENSILE LOAD }\end{array}$ & 34.98 \\
\hline 6 & FRACTURE & WELD \\
\hline 7 & SPECIMEN SHAPE & FLAT \\
\hline
\end{tabular}

Table 10Radiography result of $3^{\text {rd }}$ weld coupen.

\begin{tabular}{|l|c|c|}
\hline $\begin{array}{l}\text { Film size } \\
\text { (in inches) }\end{array}$ & Identification No. & Observation \\
\hline $3 \times 5$ & $\begin{array}{c}\text { SVERI/TIG/TC4 } \\
\text { AB }\end{array}$ & NSD \\
\hline
\end{tabular}

In this experiment welding current 137A, gas flow rate 18 $1 / \mathrm{min}$, thickness $3 \mathrm{~mm}$. No any defect is obtained in radiography test and get tensile strength about $583 \mathrm{~N} / \mathrm{mm} 2$. Here weld joint is not acceptable.

\section{Experiment no.4}

For fourth experiment following parameters are considered.

The below Table 11 and Table 12 shows the result of tensile test and radiography test respectively.

Table 11 Result of Tensile test of 4th weld coupon

\begin{tabular}{|l|l|c|}
\hline Sr.No & Parameter/Description & $\begin{array}{c}\text { Actual } \\
\text { Value }\end{array}$ \\
\hline 1 & THICKNESS & 5 \\
\hline 2 & WIDTH & 20 \\
\hline 3 & AREA & 100 \\
\hline 4 & $\begin{array}{c}\text { ULTIMATE } \\
\text { TENSILE STRNGTH }\end{array}$ & 621.00 \\
\hline 5 & SPECIMEN SHAPE & FLAT \\
\hline 6 & $\begin{array}{c}\text { ULTIMATE } \\
\text { TENSILE LOAD }\end{array}$ & 62.10 \\
\hline 7 & FRACTURE & WELD \\
\hline
\end{tabular}

Table 12 Result of Radiography Test of $4^{\text {th }}$ weld coupon

\begin{tabular}{|c|c|c|}
\hline $\begin{array}{c}\text { Film size (in } \\
\text { inches) }\end{array}$ & Identification No. & Observation \\
\hline $3 \times 5$ & $\begin{array}{c}\text { SVERI/TIG/TC4 } \\
\text { AB }\end{array}$ & NSD \\
\hline
\end{tabular}

In this experiment welding current 137A, gas flow rate 21 $1 / \mathrm{min}$, thickness $5 \mathrm{~mm}$. No any defect is obtained in radiography test and get tensile strength about $621 \mathrm{~N} / \mathrm{mm} 2$. Here weld joint is acceptable.

\section{CONCLUSION}

All the experimental steps were carried out under precautionary measures in order to keep the error factor low and to increase the reliability of the results. The following conclusions were arrived from the non destructive testing i.e. Radiography testing investigation. As current decreases minor defects are formed such as under fill. Also as current increases heat affected zoneincreases as well porosity increases. For medium current good quality weldobtained.The radiography results showed the defect of minimum porocity, thus the result concludes that the defect does not create a major impact.

According to Destructive testing following conclusion is arrived. The tensile test has showed that the Current of 137A, Gas flow rate $21 \mathrm{l} / \mathrm{min}$ and a Thickness $5 \mathrm{~mm}$ offers the maximum tensile strength of $621 \mathrm{MPa}$. The tensile test has also showed that the Current of 137A, Gas flow rate 18 1/min and a Thickness $3 \mathrm{~mm}$ offers the minimum tensile strength of 583.00 MPa.

\section{REFERENCES}

[1] Mr.L.Suresh Kumar, Dr.S.M.Verma, P.Radhakrishna Prasad, P.KirankumarDr.T.SivaShanker "Experimental Investigation for Welding Aspects of AISI 304 \& 316 by Taguchi Technique for the Process of TIG \& MIG Welding", International Journal of Engineering Trends and Technology, Volume2,Issue2- 2011, ISSN: 2231-5381, 28-33.

[2] R.K.Rajkumar, FatinHamimi, NachimaniCharde "Investigating the Dissimilar Weld Joints of AISI 302 Austenitic Stainless Steel and Low Carbon Steel", International Journal of Scientific and Research Publications, Volume 2, Issue 11, November 2012, ISSN 2250-3153

[3] M.T.Z. Butt, M.S. Ahmad and M. Azhar, "characterization for GATW AISI 316 to AISI 316 \& SA 516 grade 70 steels with welded \&prewelded annealing conditions", Journal of Quality and Technology Management, Volume VIII, Issue II, December 2012.

[4] Harish Kumar D,,A. Somireddy, K. Gururaj, "A review on critical aspects of 316ln austenitic stainless steel weldability", International Journal of Materials Science and Applications 2012; 1(1), December 30, 2012, 1-7.

[5] C.Balaji , S. V. Abinesh Kumar, S. Ashwin Kumar, R. Sathish "Evaluation of mechanical properties of SS $316 \mathrm{~L}$ weldments using tungsten inert gas welding", International Journal of Engineering Science and Technology (IJEST), Vol. 4 No.05 May 2012, ISSN : 0975-5462,2053- 2057.

[6] Akash.B.Patel , Prof.Satyam.P.Patel . "The Effect of Activating Flux in Tig Welding", International Journal of Computational Engineering Research, Vol, 04,Issue, 1, January2014, ISSN 2250-3005,65-70

[7] B. Ramesh Kumar, "weld quality analysis of TIG, laser and electron beam welded SS 304 and 316 materials with NDT techniques", Proceedings of the National Seminar \& Exhibition on Non-Destructive Evaluation NDE 2011, December 8-10, 2011,346-349.

[8] Balaji Chandrakanth, S. V. Abinesh Kumar, S. Ashwin Kumar, R. Sathish, "Optimization and Non-destructive Test Analysis of SS316L Weldments Using GTAW", Materials Research, Received: February 18, 2013; Revised: October 12, 2013.

[9] E. Ahmadi , A.R. Ebrahimi, "The effect of activating fluxes on 316L stainless steel weld joint characteristic in TIG welding using the Taguchi method", Journal of Advanced Materials and Processing, Vol.1, No.1, 2012,55-62. [10] Pradeep Deshmukh, M. B. Sorte, "Optimization of Welding Parameters Using Taguchi Method for Submerged Arc Welding On Spiral Pipes". 